\title{
TETRAEDRO Mergulhar em diferentes anterioridades para que 0 depois não seja só agora
}

\author{
Anabela Mendes
}

Anabela Mendes

é Professora da

Faculdade de Letras da Universidade de Lisboa

e investigadora do

Centro de Comunicação

e Cultura da

Universidade Católica

Portuguesa. Entre os

projectos que vem

desenvolvendo conta-

se actualmente a

concepção e preparação

do colóquio

internacional e

transdisciplinar Viagens

de longo curso:

Roteiros e mapeações,

a realizar em Maio de

2014, que juntará em

Lisboa e nos Açores

investigadores e amigos com quem se

foi cruzando ao longo da sua vida académica.
Alexandre Pieroni Calado e Sandra Hung, ambos actores, encenadores e formadores, desenvolvem actualmente um projecto teatral em torno da peça Quarteto de Heiner Müller, cuja estreia aconteceu em Setembro, na Latoaria um novo espaço das artes, situada nas Escadinhas do Monte, no 9, ao cimo do Intendente, em Lisboa.

Lugar de artes e oficios que davam forma à folha de Flandres, a aços e a zincos, a Latoaria mantém ainda traços que referenciam a sua anterior história: há objectos que passaram a ter outro uso, há estruturas que escondem os gatos de quintais vizinhos que gostam de assistir a espectáculos. A pequena loja ao fundo de um corredorpátio é hoje, com a chegada dos seus novos inquilinos, uma casa que alberga diversos artistas cujas actividades profissionais se tornaram na razão de ser da divisão desse espaço e que em torno dele têm vindo a construir uma mini-comunidade de aprendizagem e sobrevivência colectivas no respeito mútuo pelas necessidades e emergências de cada projecto.

A preparação do espectáculo Quarteto, encenado por Alexandre Pieroni Calado e com representação dos dois criadores mencionados, contempla agradavelmente uma ligação científico-pedagógica que faz parte da proposta dramatúrgica alargada a um público convidado a descobrir o modus faciendi do objecto artístico enquanto processo e não apenas como resultado. A diferenciação opcional para pré-espectadores foi criada a partir de quatro módulos intitulados de Quasiconferências, apresentadas entre Abri e Junho na Faculdade de Ciências e Tecnologia, UNL, no Monte da Caparica. Com a presença de convidados (um por sessão e em áreas distintas do conhecimento), que aceitaram tomar em mãos o mesmo objecto de partida, a peça de Müller tornou possivel criar afinidades e momentos de perplexidade onde antes eles não existiam nomeadamente porque o Quarteto foi aberto à discussão pública através de propostas de conceptualização, leitura metodologias e pré-representação encontradas pelos dois responsáveis do projecto.

A criação quase implícita da figura do pré-espectador e a sua solicitação para que se envolva em presença activante na modelação de um espectáculo que ainda não sabe o que vai ser e talvez nunca o venha a saber, é uma prática artística com risco e pouco comum entre nós. Calado e Hung, ao convocarem para o processo artístico, a um tempo, outros criadores e investigadores, a outro tempo, espectadores que se desafiam a participar neste exercício de diálogo estimulante pretenderam activar um relacionamento intelectual e afectivo entre anónimos e não-anónimos que, num caminho claramente em progressão, embora aberto para várias frentes, vão sendo envolvidos intencionalmente de forma responsável na pré-construção comum de um espectáculo artístico. Esta estratégia pressupõe que o contributo de cada um (de um lado criadores de diferentes áreas do conhecimento artístico: dramaturgia, representação, encenação, música, coreografia; do outro alunos e professores de uma Faculdade de Ciência Pura e Aplicada) se torne proporcional ao que é variável em processo de formação específica em relação à própria diferenciação entre as áreas de conhecimento agilizadas para diálogo, o grau de experiência de vida, mas também o investimento que é feito num processo colectivo.

De certo modo, a natureza deste projecto em torno de Quarteto de Heiner Müller sublinha também e de forma assumida a vontade de os dois autores do projecto validarem uma prática artística e metodológica que se socorre objectivamente de materiais e encenações que antecedem a sua própria encenação e que circulam como registo no espaço da Internet. Esta opção de visita a arquivos de modo deliberado e consequente não é nova em si e continuará a acontecer, esperemos que de forma saudável. Aquilo que se constitui como invulgaridade é o facto de existir no trabalho de Calado e Hung uma apropriação do trabalho de outros integrada e explicitada no percurso escolhido pela encenação de que são responsáveis. No espaço da representação são invocados não só como personagens que se assumem e nomeiam, colegas participantes em espectáculos "visitados" durante o período de pesquisa e consolidação de ideias em torno de Quarteto, como também se verifica uma apropriação de gestos e movimentos, de entoações vocais que passam a pertencer em simultâneo a vários objectos artísticos, 


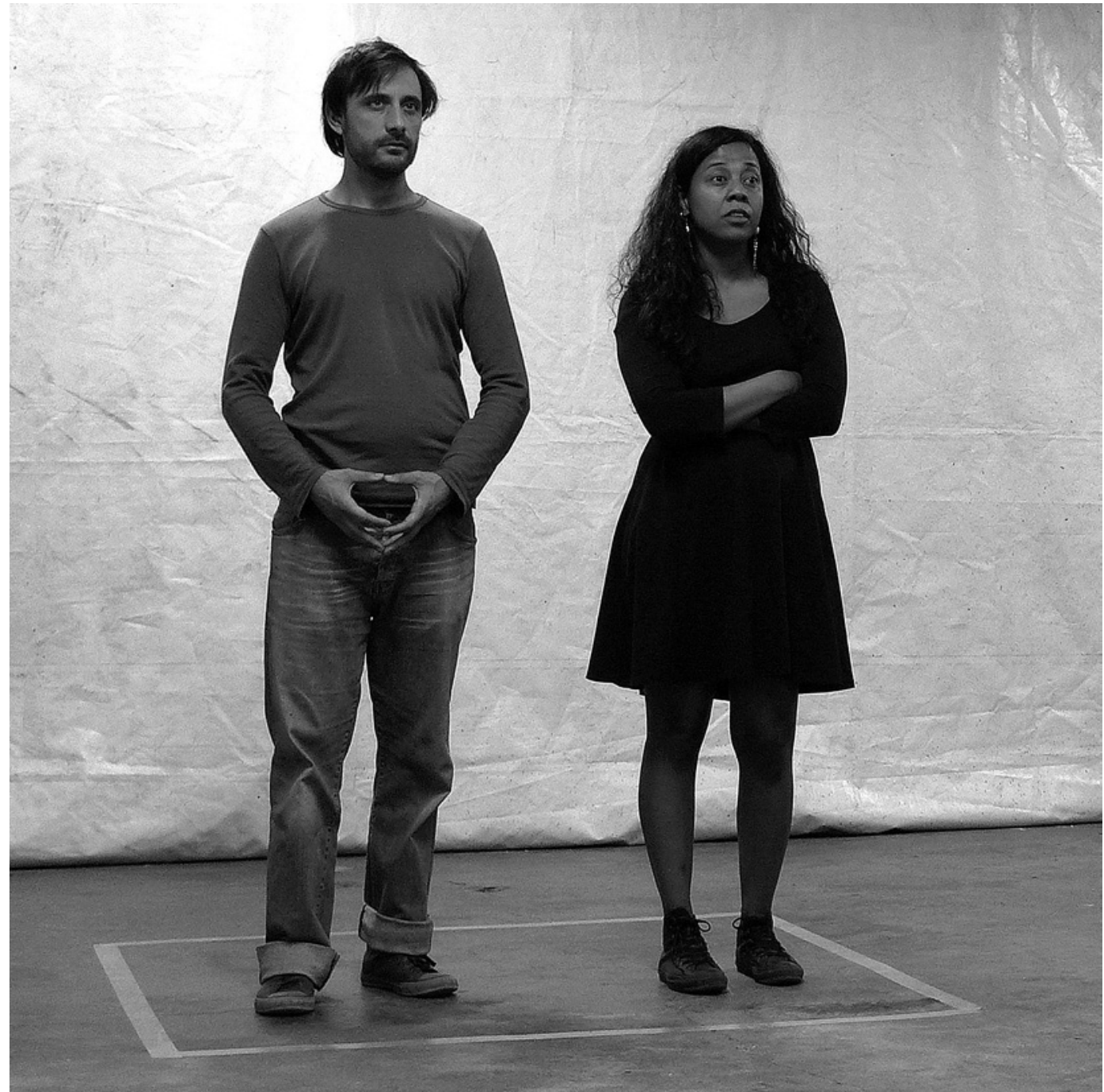

Quarteto,

de Heiner Müller,

dir. Alexandre Pieroni Calado e Sandra Hung Projecto Tetraedro Latoaria (Lisboa), 2013 (Alexandre Pieroni Calado e Sandra Hung), fot. Rodrigo Duarte.

quer correspondam nesse "aqui e agora" a distintos passados devolvidos pelo registo videográfico em arquivo, quer se tornem disponiveis para um novo percurso interpretativo.

Muito do que teve lugar nas Quasiconferências surge no espectáculo Quarteto de Heiner Müller: as partituras electroacústicas de João Ferro Martins, alagadas por um insuspeito e novo Johann Sebastian Bach, a revisitação ao ciclo da Bela moleira de Schubert, a incorporação do matraquear de uma máquina de escrever numa directa referência ao modo como Müller registava os seus textos.

0 movimento coreográfico de Bruna Antonelli, deliberadamente devedor de informação digital mas não apenas essa, opta amiúde pelo registo parodístico, pela caricatura a uma estreiteza sentimental e hipócrita que cabe bem no texto de Müller para criar oposição à predadora saciedade da carne. 0 trabalho de corpo de Calado e, em particular, a mostração de gestos como tiques doentios identifica-o com a falsidade da "verdade pura" (Kant e Kleist), aquela que Müller mantém em suspensão nesta sua peça. São ainda os processos de repetição e desconstrução do movimento que Calado e Hung executam com rigor e acuidade que transformam as danças de salão do séc. XVIII, mas também a coreografia pop, num desenho de movimento desconcertante e esvaziado dos seus sentidos primeiros, porque deixou de ser possivel olhar para essas manifestações artísticas com candura e devoção, independentemente da relação de gosto que elas possam suscitar.

Este espectáculo, no âmbito do projecto TETRAEDRO, que já contempla uma próxima investida arquivistica Woyzeck de Georg Büchner pelo Teatro da Cornucópia (1978) e que já deixou para trás Pregação pel' 0 Bando (1989), inspirado, entre outros, em obra do Padre António Vieira - deverá continuar a circular no Teatro Joaquim Benite em Almada, no mês de Novembro, e em Vale de Barris n'O Bando em Dezembro.

0 hoje só se pode considerar como tal, porque nele existe e sempre existirá o que já foi hoje e se tornou passado. Sem a percepção dessa construção que nos ajuda a compreender a relação espácio-temporal em que nos situamos, dificilmente seríamos capazes de apreender diferentes passados entre si e co-relacionados com o presente de cada um. Para que tudo isto faça sentido possuimos ainda um bem natural a que chamamos memória. É através dela, como factor inato e de aprendizado, que estabelecemos uma indissociabilidade entre passado, presente e futuro.

0 continuum da História, neste caso da História das Artes Performativas, tem no projecto de Calado e Hung um exemplo de como é possível talvez não "mudar o mundo", como desejava Müller, mas ir tentando mudálo de cada vez que se mergulha a fundo e com interesse 


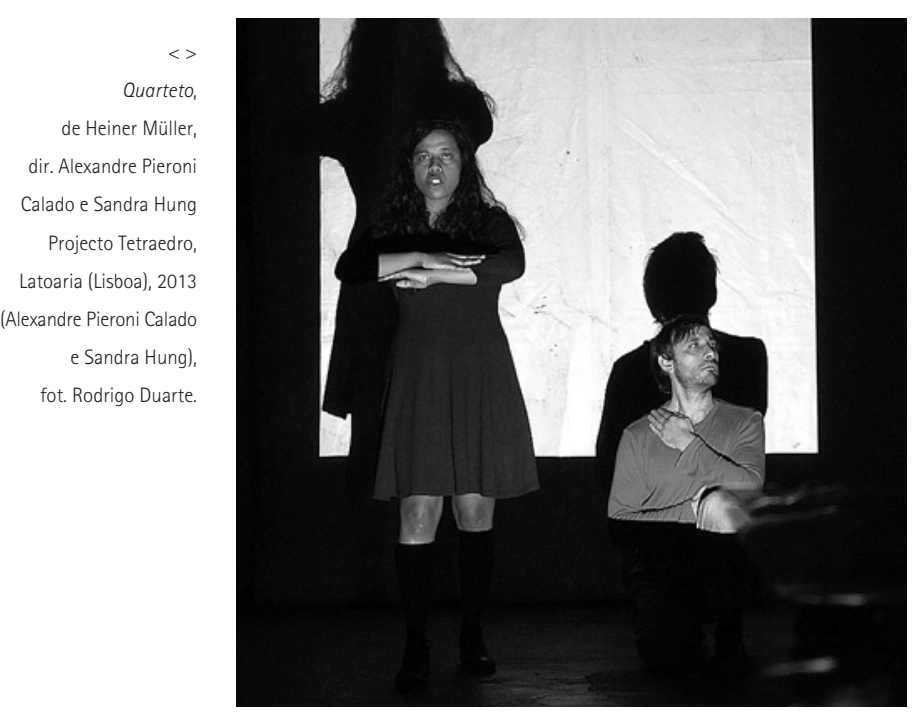

naquilo que outros fizeram. Estamos aqui perante a verdadeira arte de quem investiga com a responsabilidade de dar a conhecer as fontes no modo da citação e da reapropriação, sabendo que haverá sempre materiais que na sua casualidade se podem transformar em caso de estudo a que é possivel atribuir nova existência.

A aplicação do método e da estratégia de arquivo às artes performativas nasceu em relação ao Quarteto de Heiner Müller, para Calado e Hung, da vontade de observar como outros tinham resolvido levar à cena um mesmo texto, atribuindo-Ihe opções estéticas diferentes. Foram por isso visitados vídeos de duas encenações portuguesas disponiveis no arquivo global, a saber: a encenação da Seiva Trupe (2003) e a encenação do Teatro Praga (200607). Para além dos objectivos de comparação entre 0 existente e o que estava a nascer e da apropriação consciente de um conjunto de possibilidades a explorar na nova encenação, esta metodologia recuperava a consciência possivel de uma história da peça Quarteto, em Portugal, se bem que nem toda a história da mesma integrasse o percurso desta obra anterior ao uso videográfico no ciberespaço. É o caso, por exemplo, da encenação de Jorge Silva Melo, também actor na versão para português de Quarteto, traduzida por Maria Adélia Silva Melo, para os encontros ACARTE de 1988. 0 encenador partilhava o protagonismo da representação com Glicínia Quartin. Este

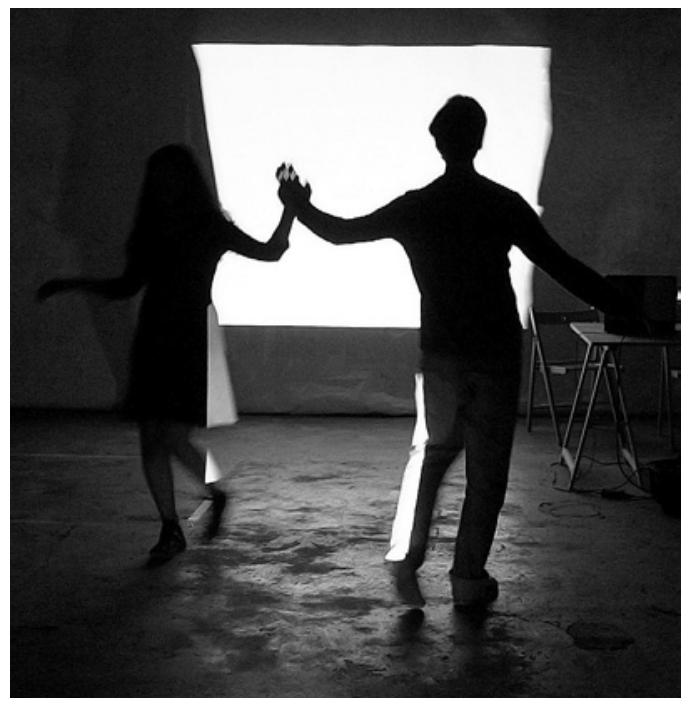

era ainda um tempo irrevisitável hoje por quem quer que seja. Aqui o sentido de arquivo global ainda não fazia jus à sua infinita capacidade de propiciar informação.

0 amplo alcance do projecto TETRAEDRO releva do facto de que ele não só se vai fazendo enquanto busca arquivistica sobre materiais para transformação e elaboração dramatúrgica (a pesquisa tradicional nunca foi excluída) como também se torna operável através de discursividade e apelo à participação de outros exteriores ao processo, num primeiro momento, alheios à construção do espectáculo, i. e., aqueles que poderíamos considerar como préespectadores. Um pré-espectador é alguém que se deseja preparar para assistir a um espectáculo enquanto seu fazedor activo.

Recorrer a fragmentos que representam etapas de uma possivel História do Teatro Português, ela mesma parte de uma mais vasta História do Teatro, atribuindoIhe o estatuto de documento não esgotado que ilustra e integra uma nova realidade de um texto dramático como processo ao mesmo tempo continuado e parcelado porque propicia num determinado contexto a sequência integrada de vida da peça e Ihe fornece também autonomia - pareceu a Calado e a Hung poder constituir um estimulante núcleo de questões para o trabalho de preparação e realização do Quarteto de Heiner Müller que agora se acrescenta à sobrevida desta peça. 